\title{
Bilateral Variations of the Testicular Vessels: Embryological Background and Clinical Implications
}

\author{
Yogesh Diwan, Rikki Singal1', Deepa Diwan, Subhash Goyal', Samita Singal'², Mausam Kapil ${ }^{1}$ \\ Department of Anatomy, Indira Gandhi Medical College, Shimla, 'Surgery and '2Radiology, Maharishi Markandeshwer Institute of Medical \\ Sciences and Research, Mullana, Ambala, India
}

\section{A B S T R A C T}

Variations of the testicular vessels were observed during routine dissection of the posterior abdominal wall in a male North Indian cadaver. On the right side, the testicular vein drained into the right renal vein and the right testicular artery passed posterior to the inferior vena cava. The left testicular vein was composed of the lateral and medial testicular veins which drained into the left renal vein independently. Left renal vein had received an additional tributary, first lumbar vein, and the left testicular artery had hooked this additional tributary to run along its normal course.

KEY WORDS: Inferior vena cava, renal vein, testicular artery, testicular vein

\section{INTRODUCTION}

The testicular arteries arise anteriorly from the abdominal aorta, a little inferior to the renal arteries. The vertebral level of their origin varies from the $1^{\text {st }}$ to the $3^{\text {rd }}$ lumbar vertebrae. Each passes inferolaterally under the parietal peritoneum on the psoas major. The right testicular artery commonly passes ventrally to the inferior vena cava. Each artery crosses anterior to the genitofemoral nerve, ureter and the lower part of the external iliac artery and passes to the deep inguinal ring to enter the spermatic cord and travel via the inguinal canal to enter the scrotum. ${ }^{[1]}$ Along their course, the testicular arteries are accompanied by the testicular veins. The testicular veins originate from the pampiniform plexus that is formed by the union of small veins from the testis and epididymis. The pampiniform plexus surrounds the testicular artery to proceed cranially and unites to form two or three venous trunks at the level of the deep inguinal ring. At the lumbar region, the venous trunks coalesce generally to form a single testicular vein that courses ventral to the ureter and accompanies the artery of the same name to ascend. The right testicular vein usually drains into the inferior vena cava, and the left testicular vein joins the left renal vein. ${ }^{[2]}$ Though these anatomical features of the testicular

\begin{tabular}{|l|l|}
\hline \multicolumn{2}{|c|}{ Access this article online } \\
\hline Quick Response Code & Website: \\
\hline & www.jbcrs.org \\
\cline { 2 - 2 } & \\
\hline
\end{tabular}

vessels are relatively constant, occasional developmental and anatomical variations have been reported. However, variations of the testicular veins associated with variations of the testicular arteries are seldom seen. ${ }^{[3]}$

In the present report, we investigate the drainage, course, tributaries of the testicular veins, the origin and course of the testicular arteries, and discuss their embryogenesis and clinical significance. Variations of these testicular vessels may reflect the complicated embryogenesis in this area. The knowledge of detailed anatomy is helpful in understanding the clinical condition and the various pathological situations related to the testicular vessels.

\section{CASE REPORT}

During the routine dissection of the abdominal region of an adult male cadaver, bilateral variations of testicular vessels were found. Variations of the testicular veins were observed bilaterally. The left testicular vein was composed of two venous trunks: The medial and lateral testicular veins [Figures 1 and 2]. The left medial testicular vein was double the width of the left lateral testicular vein. Both these veins crossed ventrally over the ureter and accompanied the left testicular artery to course cranially after leaving the deep inguinal ring. The left medial testicular vein $(19 \mathrm{~cm}$ long) ascended along medial to the left testicular artery,

Address for correspondence
Dr. Yogesh Diwan,
Department of Anatomy, Indira Gandhi Medical College, Shimla, India.
E-mail: drydiwan@gmail.com




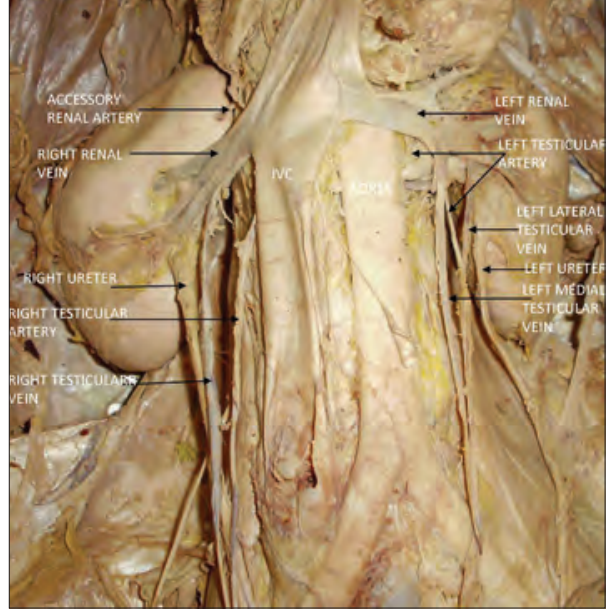

Figure 1: Right testicular vein drains into the right renal vein, right testicular artery is passing dorsally to the IVC, and duplication of left testicular vein is seen. In addition, an accessory renal artery to the upper pole of the right kidney is seen. IVC, inferior vena cava

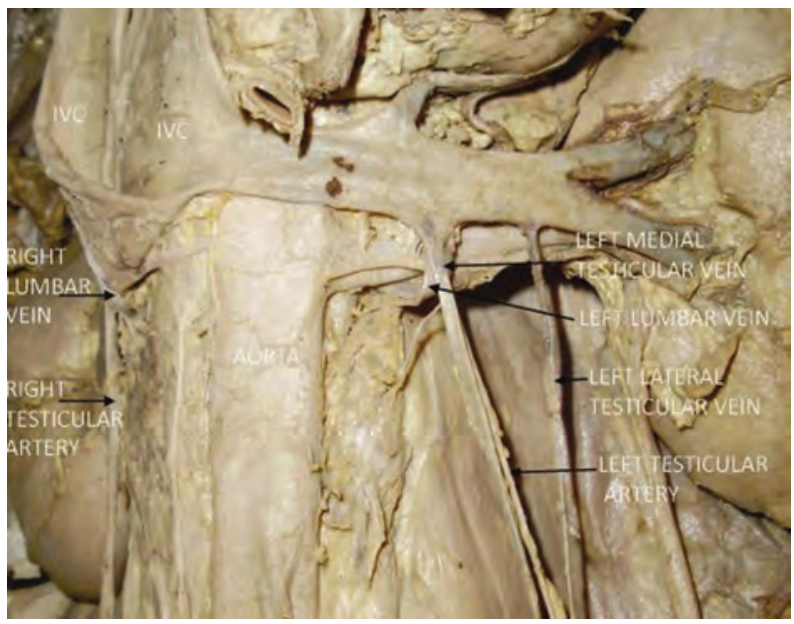

Figure 2: IVC has been turned upwards to show right testicular artery sandwiched between IVC dorsally and right lumbar vein ventrally. Left testicular artery is seen hooking the left lumbar vein and passing dorsally to the left medial testicular vein. IVC, inferior vena cava

then crossed ventrally over the artery, and finally terminated at an obtuse angle on the inferior aspect of the left renal vein just anterior to the termination of the left lumbar vein into the left renal vein. The left lateral testicular vein passed dorsal to the left testicular artery, coursed cranially, and drained into the ipsilateral renal vein lateral to the left medial testicular vein at a right angle. On the right side, the right testicular vein (17 cm long) left the deep inguinal ring, crossed ventrally over the psoas major and ureter, and ascended cranially at first along with the right testicular artery, then lateral to it and finally terminated on the inferior aspect of right renal vein at an obtuse angle.

The right testicular artery arose from the right anterolateral surface of the abdominal aorta at the level of the origin of the right renal vein, and then it passed dorsally to the inferior vena cava, just superior to the termination of right lumbar vein into the IVC, and run inferolaterally under the parietal peritoneum on psoas major, accompanied by the right testicular vein, crossed anterior to the ureter and proximal part of external iliac artery [Figures 1 and 2]. Finally, it passed into the deep inguinal ring to enter the spermatic cord with its other constituents. The left testicular artery arose from the left anterolateral surface of abdominal aorta at the level of the origin of left renal artery and $1.3 \mathrm{~cm}$ below the level of origin of the right testicular artery [Figures 1 and 2]. It passed dorsally to the first lumbar vein and left medial testicular vein, and then run between the two left testicular veins, crossed ventrally over the ureter and followed a normal course.

\section{DISCUSSION}

Anomalous blood vessels are always interesting from a purely scientific point of view, especially since they so often shed light on obscure problems of phylogeny and ontogeny. ${ }^{[4]}$ The variations in the number, unusual course and atypical drainage of testicular veins are attributed to their embryologic origin. ${ }^{[1,3,5]}$ The embryogenesis of IVC involves the development, regression, anastomosis and replacement of three pairs of venous channels: Posterior cardinal, subcardinal and supracardinal. ${ }^{[6]}$ Anastomosis between the supracardinal and the subcardinal veins, which occur bilaterally, form the renal segment of IVC. ${ }^{[7]}$ When this communication has been established, the left subcardinal vein disappears, only its distal portion remains as the left testicular vein. Therefore, the right subcardinal vein becomes the main drainage channel and develops into the renal segment of the inferior vena cava, right renal vein and right testicular vein. Variations of the testicular veins are caused by dysplasia of the subcardinal venous system in the seventh to eighth week of embryogenesis. ${ }^{[5]}$ Since the testicular vein is closely related to the inferior vena cava in embryogenesis, variations of the testicular veins may accompany abnormalities of the inferior vena cava such as duplication of the inferior vena cava. ${ }^{[8,9]}$ Variations of the testicular veins without duplication of the inferior vena cava have also been reported previously ${ }^{[10,11]}$ Out of 150 cases, bilateral variations in testicular veins were found only in 6 cases and combined venous and arterial variations were seen only in one cadaver. ${ }^{[3]}$ Drainage of right testicular vein into inferior renal vein has been reported when there are associated variations of right renal vessels. ${ }^{[12]}$ When the testicular vein is double, the right testicular vein drains into the right renal vein and IVC, while on the left side both testicular veins drain into left renal vein. ${ }^{[13,14]}$ In our case testicular vein is double on left side only and both drain into left renal vein. Varicocele has been shown to result in ipsilateral testicular atrophy and diminished fertility and up to $50 \%$ of patients suffering from it have semen alterations. The management strategies in these cases usually include 
different types of surgical and radiological interventions. Percutaneous diagnostic venography and occlusion of the incompetent veins require accurate definition of the anatomy of the testicular veins. ${ }^{[3]}$

Notkovich $^{[15]}$ classified right gonadal arteries (RGAs) into three types according to their relation to the left renal vein. Type I comprised the RGAs arising from the abdominal aorta below the level of the left renal vein and then passing ventrally or dorsally to the inferior vena cava. Types II and III comprised RGAs passing dorsally to the inferior vena cava at and above level of the left renal vein, respectively. He documented that type I is common and that $6 \%$ of type I run dorsally to the inferior vena cava. In our case the right testicular artery is of type I of Notkovich. This type of right testicular artery was reported in 1 case,,$^{[9,16]}$ in $0.8 \%$ cases $^{[17]}$ and in $0 \%(0 / 59)$ cases. ${ }^{[18]}$ The retrocaval passage of the right testicular artery can also be explained in terms of embryology. Testicular arteries represent persistent lateral splanchnic branches of dorsal aorta that enter the mesonephros, crossing ventral to the supracardinal vein and dorsal to subcardinal vein. Usually, the lateral splanchnic artery which persists as the right testicular artery passes anterior to the supracardinal anastomosis. When it passes posterior to this anastomosis in the embryo, the right testicular artery is located behind the IVC in the adult. ${ }^{[19]} \mathrm{On}$ left side, a lumbar vein of $6 \mathrm{~mm}$ diameter drains into the left renal vein which is considered as minor left renal variant. ${ }^{[20]}$ These minor venous variations were found in $40 \%$ of cases and they influence the planning of donor laparoscopic dissection in kidney transplantation cases but they did not alter the venous anastomosis procedure in the recipient. ${ }^{[21]}$ The hooking of left testicular artery around the first lumbar vein, a posterior tributary of left renal vein, can be explained by the persistence of upper lateral splanchnic artery, which persists as left testicular artery and with the descent of testis hooks around the posterior tributary of the left renal vein. Various morphological anomalies of the testicular arteries may be clinically important due to their influence on the blood flow to the testis and development of new operative techniques (especially laparoscopic surgery field) within the abdominal cavity. ${ }^{[17]}$ Also an aberrant artery supplying the upper pole of right kidney is a direct branch from abdominal aorta. More than one artery supplying a kidney is the most common arterial variation, and this is seen in about $24 \%$ cases. ${ }^{[22]}$ With the advancement of new operative techniques within the abdominal cavity, the anatomy of gonadal vessels has assumed much more importance. The gonadal vessels must be preserved to avoid the possible complications following damage of these vessels. Many complications may arise during laparoscopic surgery of the male abdomen and pelvis, due to unfamiliar anatomy in the operative field. ${ }^{[22]}$ Knowledge of these variations will serve as a reference for avoiding clinical complications during surgery in this region.

\section{REFERENCES}

1. Healy JC, Mundy AR. Testes and epididymes. In: Standring S, editor. Gray's anatomy. $39^{\text {th }}$ ed. Edinburgh: Elsevier Churchill Livingstone; 2005. p. 1306-7.

2. Yang CY, Xue HG, Tanuma K, Ozawa H. Variations of the bilateral testicular veins: Embryological and clinical considerations. Surg Radiol Anat 2008;30:53-5.

3. Asala S, Chaudhary SC, Masumbuko-Kahamba N, Bidmos M. Anatomical variations in the human testicular blood vessels. Ann Anat 2001;183:545-9.

4. Gupta A, Gupta R, Singhla RK. The Accessory Renal Arteries: A Comparative Study in Vertebrates with Its Clinical Implications. J Clin Diagn Res 2011;5:970-3.

5. Carlson BM. The development of the circulatory system. In: Carlson BM, editor. Patten's foundation of embryology. New York: MacGraw Hill; 1988. p. 586-27.

6. Lelli F, Maranillo E, Valderrama CFJ. Arched and retrocaval testicular arteries: A case report. Eur J Anat 2007;11:119-22.

7. McClure CF, Butler EG. The development of the vena cava inferior in man. Am J Anat 1925;35:331-84.

8. Takagi T, Nozaka Y, Ohsawa T. Double superior vena cava with bilateral inferior vena cava. Acta Anat Nippon 1982;57:9-14.

9. Xue HG, Yang CY, Asakawa M, Tanuma K, Ozawa H. Duplication of inferior vena cava associated with other variations. Anat Sci Int 2007;82:121-5.

10. Bensussan D, Huguet JF. Radiological anatomy of the testicular vein. Anat Clin 1984;6:143-54.

11. Lechter A, Lopez G, Martinez C, Camacho J. Anatomy of the gonadal veins: A reappraisal. Surgery 1991;109:735-9.

12. Nayak BS. Multiple variations of the right renal vessels. Singapore Med J 2008;49:e153-5.

13. Gurbuz JM, Akalin A, Gumusen B, Cavdar S. Clinical implications of concomitant variations of the testicular, supra-renal and renal veins: A case report. Ann Anat 2002;184:35-9.

14. Favorito LA, Costa WS, Sampaio FJ. Applied anatomic study of testicular veins in adult cadavers and in human fetuses. Int Braz J Urol 2007;33:176-80.

15. Notkovich $\mathrm{H}$. Variations of the testicular and ovarian arteries in relation to the renal pedicle. Surg Gynecol Obstet 1956;103:487-95.

16. Nayak SR, JJP, DCosta S, Prabhu LV, Krishnamurthy A, Pai MM, Prakash. Multiple anomalies involving testicular and suprarenal arteries: Embryological basis and clinical significance. Rom J Morphol Embryol 2007;48:155-9.

17. Onderoglu S, Yuksel M, Arik Z. Unusual branching and course of the testicular artery. Ann Anat 1993;175:541-4.

18. Terayama H, Yi SQ, Naito M, Qu N, Hirai S, Kitaoka M, et al. Right gonadal arteries passing dorsally to the inferior vena cava: Embryological hypothesis. Surg Radiol Anat 2008;30:657-61.

19. Ozdemir MB, Celik HM, Aldur MM. Altered course of the right testicular artery. Clin Anat 2004;17:67-9.

20. Raman SS, Pojchamarnwipnth S, Muangsomboon K, Schulam PG, Gritsch HA, Lu DS. Utility of 16-MDCT angiography for comprehensive preoperative vascular evaluation of laparoscopic renal donors. Am J Roentgenol 2006;186:1630-8.

21. Kumar S, Neyaz Z, Gupta A. The utility of 64 channel multidetector CT angiography for evaluating the renal vascular anatomy and possible variation: A pictorial essay. Korean J Radiol 2010;11:346-54.

22. Gupta A, Singal R, Singh D. Variations of Gonadal Artery: Embryological basis and clinical significance. Int J Biol Med Res 2011;2:1006-10.

How to cite this article: Diwan Y, Singal R, Diwan D, Goyal S, Singal S, Kapil M. Bilateral variations of the testicular vessels: Embryological background and clinical implications. J Basic Clin Reprod Sci 2013:2:60-2. Source of Support: Nil, Conflict of Interest: None declared 